IJOPM

16,11

20

\title{
Strategically flexible production: the multi-focused manufacturing paradigm
}

\author{
Gianluca Spina, Emilio Bartezzaghi, \\ Politecnico Di Milano, Milan, Italy \\ A ndrea Bert, \\ Consorzio MIP, Milan, Italy \\ Raffaella Cagliano \\ Politecnico Di M ilano, Milan, Italy, \\ Domien Draaijer \\ Philips Semiconductors, Nijmegen, T he Netherlands and \\ Harry B oer \\ University of T wente, The N etherlands
}

\section{Research background: beyond Fordism}

Over the past 20 years manufacturing and assembly activities have experienced many changes, not only technological but also organizational and managerial.

A wide range of innovations have been implemented across countries and industries, such as just-in-time, total quality management, concurrent engineering and others. As a result, both the internal organization of the factories and the external environment - including market demand, technology development, workforce education and expectations, labour and capital market - appear to be very different today from the general features that dominated the industrial development in the past, which is generally referred to as the Fordist paradigm. This paradigm shift has been described from both a macro and institutional perspective; see the comprehensive reviews by Roobeek[1] and Kenney and Florida[2]. A Iso, from a managerial point of view, clear-cut breaks with the consolidated Fordist practices have been highlighted. For example, Jaikumar[3] proposed new mission statements about the management of new technologies, Drucker[4] and Hayes et al.[5] put forward new principles to organize and manage manufacturing systems, others pointed out new

Financial support of "Gestione strategica dell'innovazione" by C.N.R. (National Research Council of Italy) is gratefully acknowledged. The contribution is the joint work of the authors. However, G. Spina has written: "Research background: beyond Fordism", "The operationalisation" and "The adoption of the multi-focused manufacturing paradigm within the assembly industry"; E. Bartezzaghi "The basic principles", "Research hypotheses and methodology" and "Conclusions"; R. Cagliano "T he research sample" and the A ppendices; H. Boer, D. Draaijer and A. Bert jointly the other parts of the paper. 
performance requirements; e.g., Slack[6] on the flexibility and Stalk and Hout[7] on time-based performances. How ever, with all the literature on paradigm shifts in manufacturing, some valid questions are still open:

- Can a new manufacturing paradigm be identified, despite the different strategic choices that industrial companies make and the different internal and external conditions they have to meet?

Strategically flexible production

- Is this paradigm a definite breakthrough with Fordism? Is it possible to find out a limited set of shared principles to design and manage the production systems, that pools different models and paths of innovations?

- If the paradigm exists, how can it be defined and operationalized to support empirical investigation?

- How is the emerging paradigm adopted across countries and industries?

- What is the performance improvement along specific measures that comes from the orientation to the paradigm?

- A re there different paths to achieve the full orientation to the paradigm?

This article explores the answers to some of these questions. A ssuming that a new paradigm is actually emerging, we define and operationalize it precisely, and investigate its adoption, performance improvements and innovation tracks, by using data from the International Manufacturing Strategy Survey (IMSS), a worldwide research project involving 600 companies from 20 countries, within the assembly industry.

The basic assumption about the emergence of a new paradigm entails that the different post-Fordist experiences are drawing together; also, despite the variety of strategies and innovations implemented, both organizational and technological. Indeed, the shift away from mass production to a new industrial organization has followed different paths, some of which drew enthusiastic attention but were abandoned or reshaped later on - e.g. the experiences of Volvo in Kalmar and Uddevalla and the so-called "neo-craftsmen" models. Other examples (see also [2] for a review) include the model of "flexible specialization"[8]. Cases in point are the textile district in Northern Italy and the textile machinery district of Baden-W ürtemberg. Though fascinating, "flexible specialization" appeared to be inapplicable to the most important capitalintensive sectors. A Iso, the Japanese way has been regarded as a replacement for the Fordist paradigm. The development of the just-in-time concept at Toyota since the 1950s and further refinements seem to discard the basic principles of Fordism (see, for example [9]). How ever this view has been questioned [10] and the Toyotism with its superexploitation of workers' capabilities has been depicted also as "hyper-Fordism". Indeed, western manufacturers have experienced many difficulties in adopting or adapting the Japanese style of management and way of organizing the production systems. 
IJOPM 16,11

22
Ever more companies are drifting away from Fordism, and it seems that a new paradigm is emerging, which embodies some features of the previous postFordist experiences, but also introduces radically new aspects. Based on a limited set of shared principles to design and manage production systems, the paradigm pools different models that companies implement to cope with the competition in their marketplaces and to exploit their capabilities. These principles appear to discard the traditional Fordist assumptions about strong labour specialization, heavy control hierarchies, functional organization, tradeoff management, co-ordinating mechanisms based on formal procedures and so on. Indeed, the whole research project on what we call the multi-focused manufacturing paradigm, moves from the idea that a clear distinction is needed between three levels:

(1) The techniques to innovate the production systems, that is, the technological, managerial and organizational innovations.

(2) Manufacturing models, i.e. the systemic implementations of combinations of techniques that companies select and customize, according to their internal and external environment; the implementation results in specific practices that suit the company's situation best.

(3) The emerging multi-focused manufacturing paradigm, that is a limited set of new principles that underpins the innovation techniques and pools the manufacturing models. This new paradigm is supposed to replace the prevailing modus operandi within different countries and assembly industries, which is generally referred to as the Fordist paradigm.

A vast body of literature has already investigated the adoption and diffusion of the single techniques. In addition the transferability of some successful models has been studied, e.g. the "Toyota model" - just to discover that they can hardly be imitated, due to a number of country-specific factors. The basic assumption of the present research is that the single innovative techniques are actually universal and thus relatively easy to imitate. Consistent and, hence, effective combinations of these techniques are much more difficult to achieve. Exactly which combination is the most suitable for a company depends on: contextual factors - for example relating to country; industry and company size technology; strategy and goals.

\section{The consistency of a manufacturing paradigm}

The rising of the multi-focused manufacturing paradigm comes from the environmental changes that have taken, and are still taking, place. These require companies and their production systems to adapt in order to remain effective. M any authors indicate how manufacturing should be organized in order to meet present market needs, resource availability, workforce expectations and so on (e.g. [11-13]). In addition, the effectiveness of manufacturing systems has been linked theoretically to their consistency, i.e. the fit between the component elements of the organization and its environment 
(e.g. [14]). Hayes and Wheelwright[13] distinguish external and internal consistency. External consistency refers to the match between the manufacturing strategy and the business environment of the company. Internal consistency refers to the match within the manufacturing function and across functions within the business unit. So, environmental changes call for new internal and external consistency. If the environmental changes are big enough they may not only require changes on technique level or model level but even on flexible production paradigm level.

A s effectiveness is a relative dimension, to assess the current and future strengths of the adopters of a new paradigm, internally and externally consistent, it is advisable to describe their position relative to rivals. This is in line with Pfeffer[15], who maintains that effectiveness can only be assessed comparatively. We can measure the position of a company relative to a competitor via two dimensions:

(1) its relative position regarding performance in the marketplace;

(2) the relative speed of organizational change aimed at improving performance[14].

Here we follow the second alternative, by addressing the question as to whether the multi-focused manufacturing paradigm enables a better degree of performance improvement than companies that have a lower degree of adoption of the paradigm. We expect cumulative effects on performance improvements depending on different degrees of adoption of the paradigm.

Several studies prove the effectiveness of manufacturing improvement programmes. Individual programmes proved to be associated with individual, related performance improvements, but success in manufacturing seems to require synergistic investments in a wide portfolio of programmes[16]; worldclass companies, adopting a wide range of best practices, perform well on a wide range of measures[17-18]. In addition, cumulative effects on different performances have been highlighted - see the "sandcone model"[19]- and some techniques or approaches demonstrated to improve simultaneously different performances regarded as antithetical[20], thus shifting traditional trade-offs. This kind of literature explores the practice-performance link, either individually or synergistically. In this contribution we move to the paradigmperformance link. In fact, the actual possibility to improve manufacturing performances through innovative activities depends on their proper implementation[21]. In our view, the orientation to the multi-focused manufacturing paradigm, whatever the programmes or the practices implemented, can measure the success of the implementation.

\section{The multi-focused manufacturing paradigm}

The basic principles

Recently, much has been written on the general changes that occur in the manufacturing systems. For example, [4,5] and [22] have proposed conceptual frameworks that identify a limited number of basic criteria. A II these 
IJOPM

16,11

24 contributions suggest a number of principles underpinning different manufacturing models. Though there are different emphases in those proposals, they can be regarded as coherent identifications of a unique paradigm, based on the external and internal consistency. A ctually, today's external consistency seems to require:

- multiple performances required simultaneously;

- rapid priority changes;

- time effectiveness and quick response;

- increased quality of working life; and, in general,

- more involving and motivating tasks for an increasingly educated workforce.

To match these requirements, internal consistency is needed:

- global optimization;

- process focus in the organizational design just to keep quality and time fit with customer needs;

- development of internal capabilities and local problem solving;

- alignment of the manufacturing and the new product development processes.

A ccording to [22], and integrating that framework in the light of other contributions, the multi-focused manufacturing paradigm can be articulated in three basic principles:

(1) Multi-focusedness and strategic flexibility. This first element relates to the manufacturing strategy. The multi-focused manufacturing paradigm drives companies to pursue a number of different objectives, traditionally regarded as antithetical, simultaneously, rather than focusing on specific objectives considered mutually exclusive. In addition, the paradigm implies a strategic flexibility, that is the ability to rapidly shift competitive and manufacturing priorities from one set of goals to another, within the same manufacturing system. This principle challenges the traditional assumption about rigid trade-offs involving manufacturing performances.

(2) Integration. This second element relates to production organization from a macro-structural perspective. It entails a resolute process focus, concerning especially those processes directly involved in the valueadding chain. Process integration is pursued across the internal functions and with both customers and suppliers. The previous emphasis on functional optimization should be abandoned in favour of a redesign of the company pivoted by the concepts of operating continuity, and process integrity, across the functional barriers. 
(3) Process ownership[23]. This third element also relates to production organization, from a micro-structural perspective. It aims at involving all employees at any hierarchical level, in decision making and problem solving. Delegation, involvement and knowledge of the process are embodied in this principle. The ultimate purpose is to develop at least some degree of local problem-solving capabilities, in order to detect and resolve process anomalies as soon as possible, and to avoid timeconsuming hierarchical referrals.

Both integration and process ownership are strictly related to multifocusedness. In fact, integration fosters the globalization of the goals and the strategic flexibility, making the organization more capable to follow market turbulence rapidly and to seize volatile opportunities. Process ownership is a basic contribution to enhance the quality of the outputs and to reduce the leadtime of the business processes, which in turn is the primary mechanism to reduce or, even better, avoid the trade-offs between performances traditionally regarded as antithetical. Thus the implementation of the three principles should be approached as an integrated problem, in order to achieve the required external and internal consistency.

The operationalization

The operationalization needed to investigate the adoption and the performances of the multi-focused manufacturing paradigm is based on a set of state variables that show, at a given time, to what extent a manufacturing unit is simultaneously oriented to multi-focusedness, integration and process ownership. The multi-focused manufacturing paradigm is a complex and multidimensional concept and relates to a complex system - i.e. the whole of the operations. It is difficult to describe a complex concept, using precise statements and numeric variables. Thus, the operationalization of the paradigm is necessarily based on a wide set of attributes, including also many, "linguistic variables, that is variables that are not numbers but words or sentences in a natural language"[24]. This set provides the basis to evaluate the degree of belonging of a unit to the paradigm, at a given time. In fact, the paradigm is not a "yes or no matter". T he process of adoption is supposed to be progressive over time, so that at a certain point in time, a company may show a degree of belonging to the paradigm, maybe weak, strong, or all the gradations between the two extremes. For all the above reasons we use a fuzzy-logic approach (see for instance [24]). First, the set of state variables connected to the paradigm has been identified (see the items on the right-hand side of Figure 1).

Then, membership functions were built up to relate the single state variable to the degree of belonging, ranging from 0 (non-belonging) to 1 (complete belonging). The tuning of the membership functions is based mostly upon the literature on current best practices all over the world within the assembly industry (see Appendix 1 for some examples and [25] for a complete description). Starting from the basic set of variables, a hierarchical 


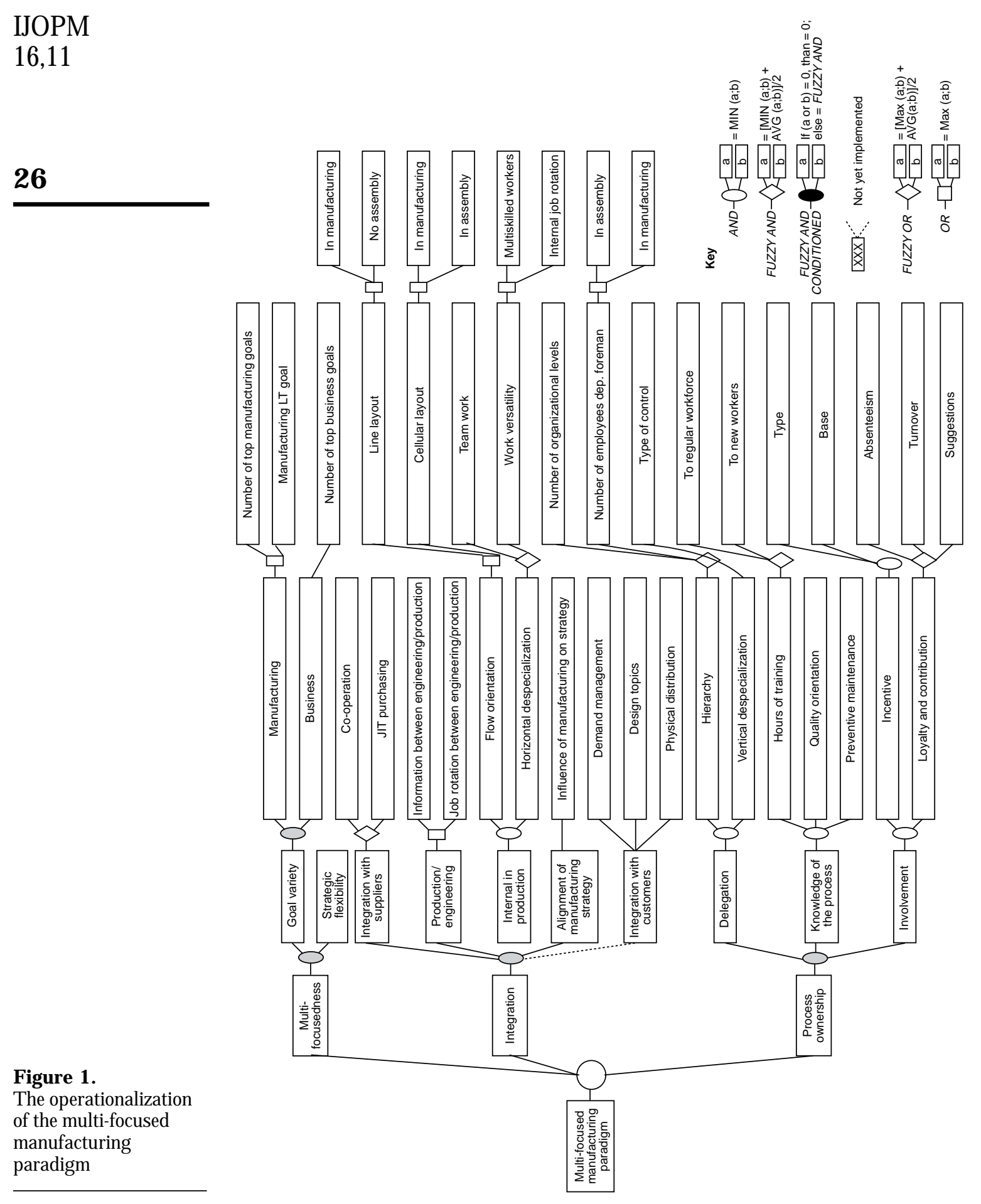


methodology was assessed that aggregates the leaves into the intermediate concepts, up to the three basic principles and to the paradigm as a whole.

Figure 1 shows the whole filter and in particular the operators we used for the aggregation of the leaves to the final degree of belonging to the paradigm (see also A ppendix 2). These are mainly FUZZY-A ND and AND operators, given the necessity of the presence at the same time of the three principles and their sub-principles. OR and FUZZY-OR operators were used when single items can be regarded as alternative with respect to the paradigm adoption. Of course, the so-computed degree of belonging to the paradigm embodies a certain degree of subjectivity, relating to the selection of the state variables, the definition of the membership functions and the logic of the aggregation. The belonging to the multi-focused manufacturing paradigm is an absolute figure, but the degree of belonging to it can be regarded as a relative concept, useful to benchmark manufacturers from different countries and industries. In addition, the tuning of both the membership functions and the parameters of the fuzzy operators influences the absolute figure of the degree of belonging, but not the rank of the units within the sample, just saving the opportunity for crosssectional comparisons. W hat is important to get a reliable rank is to select properly the OR/FUZZY-OR and the AND/FUZZY-AND operators, and the shape of the membership functions (increasing, decreasing, S-curve, step function, etc.).

Research hypotheses and methodology

The operationalization of the paradigm allows us to investigate two basic issues about the multi-focused manufacturing paradigm, respectively concerning:

(1) the adoption of the multi-focused manufacturing paradigm across industries and countries;

(2) the effectiveness of the multi-focused manufacturing paradigm, i.e. its ability to provide the adopters with superior improvement capabilities.

Two sets of specific hypotheses have been formulated for the two issues, respectively.

The adoption of the multi-focused manufacturing paradigm. We expected that some context factors may influence the adoption of the multi-focused manufacturing paradigm across industries and countries. We expect that the paradigm is adopted:

(1) Widely across countries but basically in the industrialized countries (Japan, North A merica and the most advanced European countries); the NICS and the less developed European countries will be less oriented to the multi-focused manufacturing. In fact, some unfavourable conditions are expected to hamper the paradigm adoption, such as the poverty of the public infrastructures, the shortage of a well-educated workforce, 
IJOPM

16,11

28 and low labour cost that is expected to attract mass production rather than innovation.

(2) Widely within the assembly industry and not only in the automotive industry, which attracted much of the attention since it was the cradle of both Fordism and post-Fordist experiences; we expect that the paradigm thrives also within other assembly sectors and mainly the electronic and electro-mechanical industries.

(3) By large and medium-sized companies, since they are expected to have a more robust managerial culture and to be more sensitive to managerial and organizational innovations.

The effectiveness of the multi-focused manufacturing paradigm. A s far as effectiveness is concerned, we investigated if full adoption of the paradigm results in a better performance improvement compared with companies which did not, or only partially adopted the paradigm. To address this issue we had to test:

- if companies that have adopted the principles of the paradigm are better capable of improving their performance compared to non-adopters;

- if partial adoption of the paradigm also qualifies for a better performance improvement;

- if the three principles of the paradigm reinforce each other.

A specific methodology has been built up to explore different degrees of adoption of the paradigm and the related performance improvements.

The "starmodel" in Figure 2 distinguishes companies with several degrees of belonging to the paradigm. This is also useful to study all kinds of innovation tracks which have to do with pursuing a full adoption of the paradigm.

Three classes of belonging to the paradigm can be defined (see Figure 2):

(1) complete adoption, referring to the companies which have adopted all three principles (core adopters);

(2) partial adoption, i.e. companies that adopted two out of the three basic principles (star adopters);

(3) non-adoption, referring to companies that have only one principle out of three adopted or show no adoption at all (non-adopters).

We consider a principle to be adopted if the company has a score higher - for the single principle at hand - than the mean within the sample. In order to be a core adopter a company must have a score higher than the mean within the sample for all three principles.

In summary, our major line of argument is that:

- a new manufacturing paradigm is emerging and gradually replacing Fordism; 
- it involves strategic multi-focusedness, integration of business processes across functions and process ownership;

- it can be operationalized using a fuzzy-logic approach;

- it is widely adopted across countries and industries, but there are some factors that influence its adoption;

- it results in a higher improvement capability compared to non-adopters; and

- different paths of innovation are feasible, since companies can implement the three principles according to different sequences.
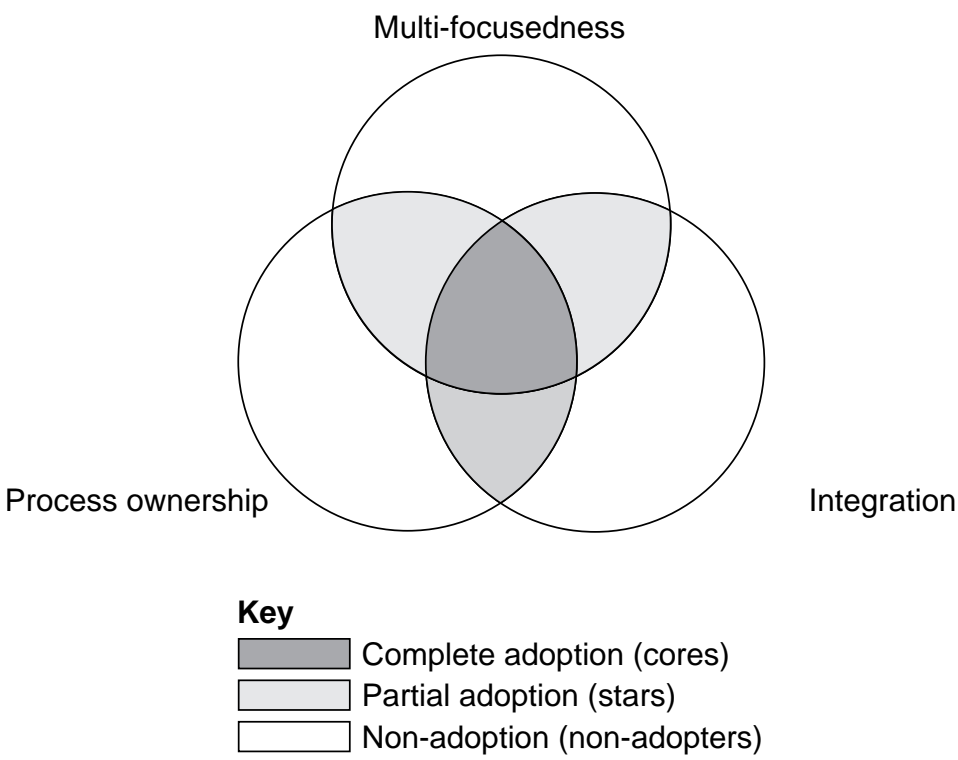

Figure 2.

The starmodel: intersection of principles

\section{The research sample}

In order to explore the emerging paradigm on a global basis, we analysed the IMSS database but had to restrict ourselves to 443 companies. In fact, due to missing answers, it was not possible to evaluate properly 157 units out of 600 , using the filter presented in Figure 1. A ppendix 3 describes the procedure used to select processable respondents. The dropping of non-processable cases has not modified significantly the distribution of the original sample of the IMSS database (600 companies). Tables I and II show the distribution of the sample by industry and country.

\section{The adoption of the multi-focused manufacturing paradigm within the assembly industry}

The multi-focused manufacturing paradigm seems to emerge on a global basis. Looking at the global sample in Table III, it appears that strategic multi- 


\section{IJOPM 16,11}

30

focusedness is on hand for most of the companies, while process ownership seems to be the least adopted. Process integration lies in between. How can we explain the widespread poor orientation to process ownership?

Our primary concern was to verify the appropriateness of the membership functions we used to score the companies. All of them appeared to be realistic, since we could find companies in the sample that reached the complete belonging to the paradigm, for each item in the filter; also for those related to process ownership. However, while a number of companies can achieve the complete orientation to the three sub-principles of process ownership -

\begin{tabular}{llc}
\hline ISIC & Description & Respondents \\
\hline 381 & Metal products (except machinery) & $142(32.1)$ \\
382 & Machinery (except electrical) & $66(14.9)$ \\
383 & Electrical machinery apparatus, appliances and supplies & $92(20.8)$ \\
384 & Transport equipment & $55(12.4)$ \\
385 & Measuring and controlling equipment, optical goods & $40(9)$ \\
- & Not specified or other & $48(10.8)$ \\
Note: Percentage in parentheses &
\end{tabular}

Table I.

Distribution of the 443

processable companies by industry (number and percentage on total sample)

Note: Percentage in parentheses

\begin{tabular}{llc}
\hline & & \\
\cline { 2 - 3 } & Country & Number \\
\cline { 2 - 3 } & Sweden & 42 \\
& Norway & 11 \\
& Finland & 16 \\
& Denmark & 13 \\
& Great Britain & 27 \\
& Germany & 18 \\
& Austria & 21 \\
& The Netherlands & 20 \\
& Belgium & 2 \\
& Italy & 34 \\
& Portugal & 24 \\
& Spain & 24 \\
USA & Canada & 33 \\
Megraphical & Mexico & 14 \\
distribution of the 443 & J Japan & 51 \\
processable companies & Australia & 28 \\
& Brazil & 21 \\
\hline
\end{tabular}




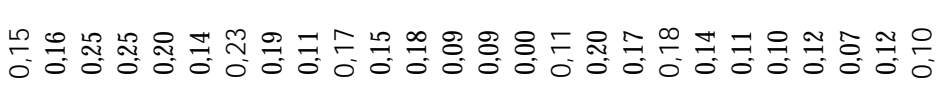

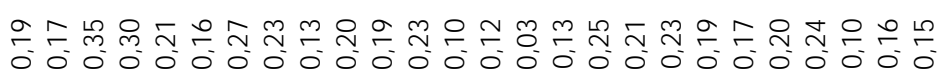

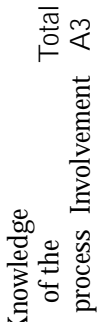
它

要罂 塞害要

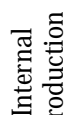
를 을 $\frac{\sqrt{0}}{\frac{0}{0}}$ 高年 旁喜政 息蛋

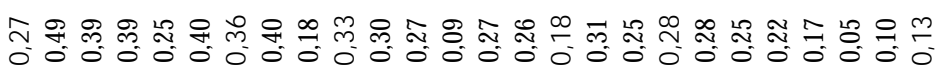

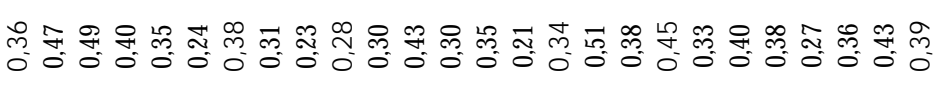

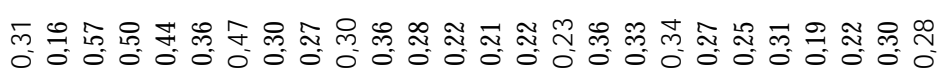

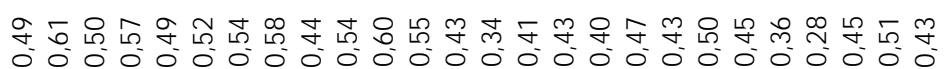

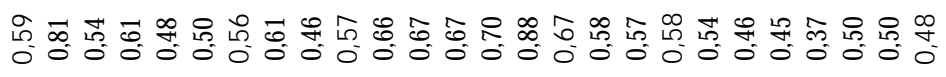

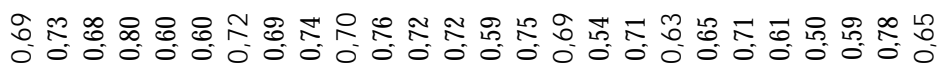

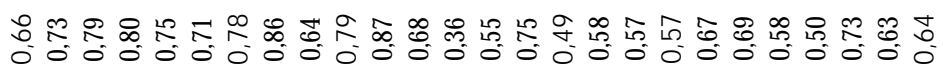

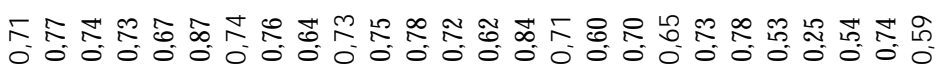

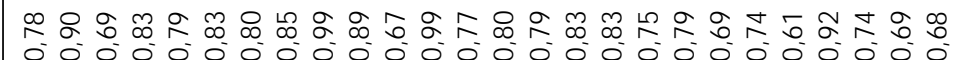

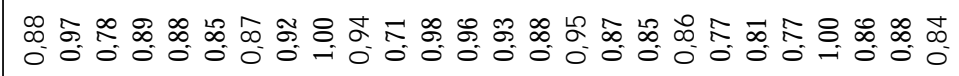

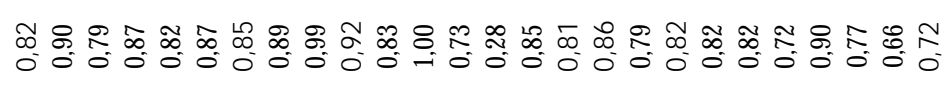

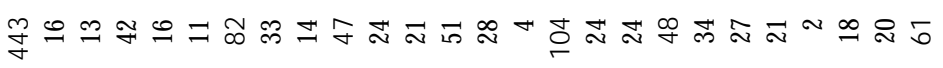

Strategically flexible production

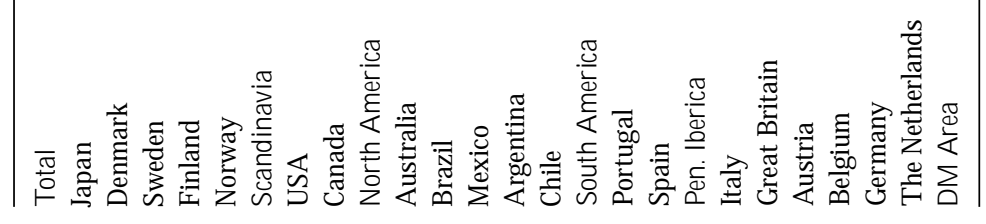

Table III. The multi-focused manufacturing paradigm around the 
IJOPM

16,11

32

delegation; knowledge of the process and involvement - separately, the sample does not comprise any company that has achieved them jointly. Indeed, many companies declare to implement multi-focusedness at the business and manufacturing level and integrate different business processes at the same time, while delegation, knowledge of the process and involvement appear, to some extent, to be mutually exclusive. This is hardly justifiable from a theoretical perspective, since the three sub-principles should reinforce one another, and no definite process ownership should be possible without the concurrency of the three sub-principles.

The possible explanation is that the adoption of the multi-focused manufacturing paradigm is a step-by-step process, in which:

- multi-focusedness is a market-driven pattern and thus first adopted;

- integration appears to be the organizational answer at a macro level to face the challenge of multi-focusedness;

- eventually, process ownership should provide the local mechanism to support the integration at a micro level.

But, on the average, it is supposed not to be fully recognized yet as the key enabling factor, at the moment. In addition, the implementation of this concept is expected to meet more organizational inertia and cultural barriers. Such a phased adoption of the multi-focused manufacturing paradigm might account for the low orientation to the process ownership; yet, it cannot be overlooked. The investigation of the effectiveness of the new paradigm clearly provides an empirical proof, since the core adopters of the paradigm achieve better and quicker performance improvements than adopters not oriented to process ownership. Our findings with respect to the five specific hypotheses are presented in the following sections.

The geo-economic context

The basic hypothesis about the diffusion of the paradigm in the most advanced countries appeared to be confirmed. The orientation to the multi-focused manufacturing paradigm seems to be present in different economic areas, even though not uniformly. The country factor is strongly related to the degree of belonging to the paradigm and also to the three principles and all their subprinciples. In fact the one-way A NOVA tests the probability $p$ that the differences in the mean score of the national samples is random less than one per cent for all the sub-principles scored in Table III. In particular, the Scandinavian area appears to be much oriented to the paradigm, with far higher levels than the mean of the sample for all the three aspects - delegation, knowledge of the process and involvement - of process ownership. A lso the average score of integration exceeds the mean of the sample and particularly the integration of production-engineering. Japanese companies confirm to be strongly oriented to the paradigm for most of the sub-principles. Integration is more pursued than elsewhere and, in particular the link between manufacturing and business strategy seems to make the difference. $M$ ainly 
because of the heaviness of the hierarchies, i.e. many organizational levels, delegation scores are very low, which negatively affects the score of the Japanese firms. In turn the knowledge of the process and the involvement score is very high. A ctually they seem to dominate the rest of the sample as to the orientation to the multi-focused manufacturing paradigm except for the delegation. Companies from the Deutschmark area show the lowest degree of belonging to the paradigm, due to the poor orientation to process ownership. In particular, the German companies in the sample score very low as to

Strategically flexible production involvement and delegation. They tend not to use group incentives, suffer higher short-term absenteeism and enjoy less improvement suggestions. Consequently, the average level of involvement is far bel ow the mean of the sample. In addition, those companies maintain a highly centralized control of the production system, which causes the low level of delegation. US companies stand out for their effort to integrate production and engineering, and they are also markedly oriented to the involvement of the workers. The multi-focused manufacturing paradigm seems to be adopted also in the NICs. For example, Brazilian companies proved to be extremely multi-focused, to pursue different kinds of process integration, and to commit themselves to develop the knowledge of the process in the workers. Indeed, the Brazilian sample is biased towards the best-practice companies, often by foreign corporation, while most of the national samples do not show such a bias.

It is interesting also to note that the philosophy of the multi-focused manufacturing paradigm seems to overcome some unfavourable national conditions, e.g. the shortage of well-educated manpower, the poverty of the infrastructures and the low labour cost that is expected to attract mass productions rather than lean ones, at least when in the track of a global, corporate culture.

The industrial context

The multi-focused manufacturing paradigm is widely adopted within the assembly industry. Widespread orientation to the paradigm has been detected not only in the ISIC 384, which in the database is mainly formed by car assemblers or car component producers. Indeed the electrical and machinery industry show the highest orientation to the paradigm on the whole (degree of adoption 0.17 and 0.19 , respectively). Multi-focusedness still remains more pursued within the transport industry (score $=0.82$ vs 0.78 in the whole sample), even though no statistical significance of the differences was discovered. On the contrary, the one-way analysis of variance (A NOVA) test revealed that the industry factor significantly affects only the process ownership ( $p=0.008$ ) and mainly delegation $(p=0.001)$ and in this case the electrical and machinery industry far exceed the other assembly industry $(0.38$ for both vs 0.27-0.29 for others).

\section{Company-size}

Company size is strongly related to the adoption of the paradigm. Small companies show lower scores than large and medium-sized ones (0.13 vs 0.18 ). 
IJOPM 16,11
The differences are statistically significant for all the three basic principles: as to the multi-focusedness ( $T$-test: $p=0.015)$ the difference mainly depends on the business level $(p=0.010)$; in the case of integration $(p=0.002)$ the dominance of large companies can be traced back to the very differential integration between business and manufacturing strategy $(p=0.000)$; finally the superior orientation to process ownership ( $p=0.003$ ) within the large companies mainly relies on their capability to develop the knowledge of the process within their workers $(p=0.050)$. Two-way A NOVA allows us to state the independent influence of the size factor. In fact, size and industry can explain separately the adoption of the paradigm within the sample, while no significant interaction was detected for all the principles and their sub-principles. Quite the same was found for sizeand country factors, though process integration shows some joint effect of the two factors. In fact, the US and the Japanese units within the sample are also larger than the other, so it is hard to extract size or country as independent factors.

\section{The multi-focused manufacturing paradigm and performance improvements}

The effectiveness of the multi-focused manufacturing paradigm is linked to the capability it gives the adopters to improve the performances of the production systems; to improve and speed up performance than the non adopters, thus catalysing the improvements arising from single action programmes. The operationalization of the different degrees of belonging to the paradigm allows us to test the hypotheses about the effects of its adoption on performance improvements, through the framework previously described - the "starmodel" - which allows us to distinguish among different degrees of adoption of the multi-focused manufacturing paradigm.

The 443 processable companies had the following distribution over the "starmodel": 83 companies (19 per cent) of the sample could be classified as core adopters; approximately 36 per cent of the companies resulted in stars - i.e. with a score higher than the mean on two principles out of three, the remaining 45 per cent represented poor scores or non-adoption at all.

It seems that the multi-focused manufacturing paradigm generally provides its adopters with a higher improvement capability compared to non-adopters.

Looking at the global sample in Table IV it appears that:

- The adopters of the paradigm are better capable of improving their performances than non-adopters on almost all performance criteria. There is a general dominance of the adopters over the non-adopters. In fact, when comparing the adopters with the rest of the sample (stars and non adopters) four differences in performance improvements are significantly better, namely: inventory turnover; speed of product development; customer service and delivery lead time (see Table IV).

- Connected with the stars and different innovation tracks we found that partial adoption of the paradigm also resulted in advantages in a subset of performances, i.e. a partial dominance over the non-adopters. 


\begin{tabular}{|c|c|c|c|c|c|c|c|}
\hline $\begin{array}{l}\text { Performance } \\
\text { criteria }\end{array}$ & $\begin{array}{l}\text { Core } \\
\text { adopters }\end{array}$ & $\begin{array}{l}\text { Stars } \\
\text { non- } \\
\text { adopters }\end{array}$ & $\begin{array}{c}\text { Average impr } \\
\text { t-test } \\
\text { significance } \\
(\%)\end{array}$ & $\begin{array}{l}\text { ovements } \\
\text { Stars }\end{array}$ & $\begin{array}{l}\text { Non- } \\
\text { adopters }\end{array}$ & $\begin{array}{c}\text { t-test } \\
\text { significance } \\
(\%)\end{array}$ & $\begin{array}{r}\text { Strategically } \\
\text { flexible } \\
\text { production }\end{array}$ \\
\hline \multicolumn{8}{|l|}{ Conformance to } \\
\hline $\begin{array}{l}\text { Unit manufacturing } \\
\text { cost }\end{array}$ & 16.80 & 12.61 & & 16.14 & 9.45 & & \\
\hline Inventory turnover & 40.87 & 22.38 & 1.9 & 28.84 & 18.01 & & \\
\hline $\begin{array}{l}\text { Speed of product } \\
\text { development }\end{array}$ & 29.49 & 15.55 & 0.8 & 18.11 & 13.76 & & \\
\hline On-time deliveries & 46.35 & 21.60 & & 27.52 & 16.63 & 1.9 & \\
\hline Equipment changeover & 25.82 & 16.21 & & 20.47 & 13.32 & 2.7 & \\
\hline Market share & 12.56 & 11.16 & & 18.97 & 5.66 & & \\
\hline Profitability & 8.12 & 10.27 & & 16.16 & 7.09 & & \\
\hline Customer service & 26.99 & 17.83 & 4.4 & 22.46 & 13.99 & 0.6 & $\begin{array}{l}\text { Table IV. } \\
\text { Performance }\end{array}$ \\
\hline $\begin{array}{l}\text { Manufacturing lead } \\
\text { time }\end{array}$ & 45.95 & 23.07 & & 31.10 & 16.35 & 0.4 & $\begin{array}{l}\text { improvements within } \\
\text { different classes of }\end{array}$ \\
\hline Procurement lead time & 36.03 & 15.12 & & 18.37 & 12.33 & & adoption of the \\
\hline Delivery lead time & 36.28 & 19.75 & 1.5 & 22.77 & 16.53 & 4.1 & multi-focused \\
\hline Product variety & 19.03 & 13.03 & & 13.06 & 12.91 & & manufacturing paradigm \\
\hline
\end{tabular}

- A s full adoption is a general dominance and partial adoption is a partial dominance as to performance improvement, the fuzzy-logic approach is enforced. This implies that the simultaneous presence of the three principles enforces improvement gains (the more you put together the more you gain).

These findings support the idea that the multi-focused manufacturing paradigm requires consistency and leads to effectiveness, since it allows companies to improve more so. The empirical evidence, and in particular the conclusion of "partial adoption is partial dominance and full adoption is general dominance", is also coherent with the idea of cumulative performance improvements[20] associated with the implementation of practices increasingly oriented to the paradigm.

Having said this, some comments must be mentioned as well. Given the data of IMSS, no strict causality can be inferred in an absolute sense between the degree of the adoption of the paradigm and performance improvements. A s Hamblin and Lettman[26] have pointed out, the usual statistical tests do not allow us to state a causal link between techniques and performances. In fact one may contend that the performance improvements, for example in inventory turnover and market share, can create additional resources (cash-flows) to be invested in the multi-focused manufacturing, so that the causal link would be the reverse (more improvements: innovation towards the multi-focused manufacturing). To state strict causality we should employ two-way models 
IJOPM

16,11

36

based on time series on the two classes of variables (as with Granger causality[27]), which we cannot do at the moment, given the non-longitudinal structure of the IMSS survey. So, from a methodological perspective we simply tested the presence of multi-focused manufacturing and performance improvements at the same time. Yet, when considering manufacturing performances (cost, delivery time, etc.) rather than business ones (profitability and market share), the causal link between the degree of adoption of the paradigm and the degree of performance improvements may be reasonably assumed.

\section{Innovation tracks}

The last purpose of this contribution is to explore the patterns that companies can follow to reach core adoption of the multi-focused manufacturing paradigm.

In theory, 13 different paths (see Figure 3) can be distinguished. The IMSS data show that some of them are more favoured by companies than are others. In the total sample:

- 16 per cent of the companies are process ownership adopters, i.e. score higher than the mean (0.19) of the sample; in other words, a relatively small number of companies score above a relatively low mean;

Multi-focusedness

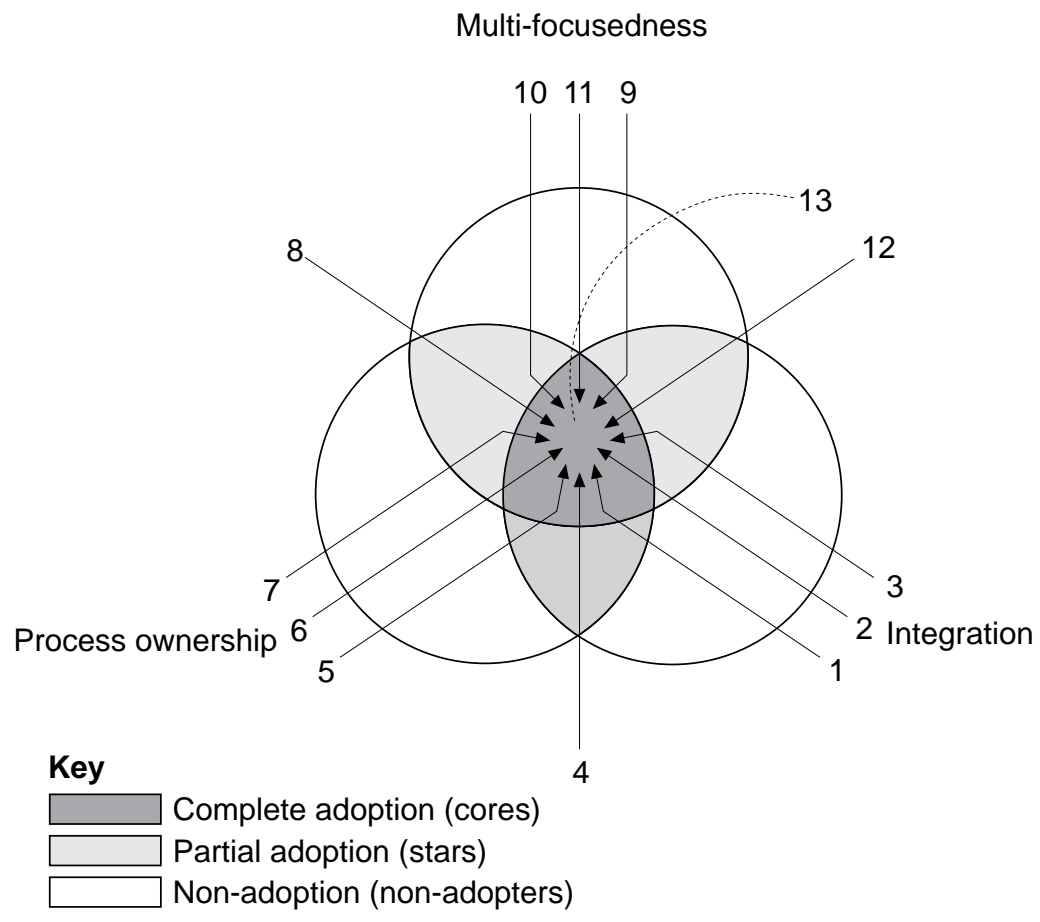

Figure 3.

Innovation tracks 
- 50 per cent of the companies are process integration adopters, i.e. score higher than the mean (0.49) of the sample: in other words, a relatively average number of companies score above a relatively average mean;

- 59 per cent of the companies are multi-focusedness adopters, i.e. score higher than the mean (0.78) of the sample: in other words, a relatively high number of companies score above a relatively high mean.

Strategically flexible production

This seems to imply that the favoured paths are those starting with the implementation of multi-focusedness. These are followed closely by those starting with the implementation of process integration. Finally, these in turn are followed on a considerable distance by those starting with the implementation of process ownership.

The different paths can be explained from a theoretical point of view as follows. A $n$ incremental approach towards full adoption starts with the implementation of process integration, followed by process ownership and, finally, multi-focusedness (path 1). This approach is an example of: "strategy follows process follows organization"; "Jobs must often be specialised vertically because they are specialised horizontally"[28]. This implies that the first logical step has to bejob enlargement (process integration), followed by job enrichment (process ownership), rather than the other way around. A more radical approach is path 4, that involves the simultaneous implementation of process integration and process ownership using, for example, semi-autonomous groups or self-managed teams. A well-known example of this approach is the Uddevalla plant[29]. These approaches lay the foundations required for the organization to become really strategically flexible (rather than "just" multifocused).

Two other approaches represent companies that start with the implementation, or are based on the presence, of multi-focusedness. Typically, companies following path 9 (multi-focusedness, then process integration and then process ownership) and 12 (process integration plus multi-focusedness and then process ownership) are multi-purpose, do-all plants and, hence, not optimally efficient. They create the necessary conditions, i.e. process integration and process ownership, not only to increase their efficiency, but also to be able to make the next step to strategic flexibility. The most radical approach provides to implement simultaneously the three principles (path 13); this case mainly occurs in a greenfield situation.

The existence of different paths that non-adopters can follow in order to become core adopters shows that companies face many options when considering the adoption of the multi-focused manufacturing paradigm. This supports the idea of the existence of a considerable design space for a company to choose its own way to the paradigm.

\section{Conclusions}

This article set the hypothesis of the emergence of the multi-focused manufacturing paradigm, based on the simultaneous implementation of 
IJOPM

16,11

strategic multi-focusedness, integration of business processes and process ownership. It also proposes a model that allows the evaluation of the orientation of a company to the paradigm and thus makes possible the investigation of its diffusion, the performance improvement capacity it provides, and the innovation paths through which companies can implement it.

The paradigm rises as a coherent set of principles underpinning the wide range of techniques and approaches for the innovation of the manufacturing systems, and provides manufacturers with a higher level of strategic flexibility. The identification of the paradigm has been based on internal and external consistency, as implied by today's business environments. Such a post-Fordist paradigm embodies both established previous experiences and radically new elements. It has been operationalized through a fuzzy-logic and hierarchical methodology. Using data from a sub-sample of 443 companies from the International M anufacturing Strategy Survey database, the adoption of the paradigm has been detected across a wide range of countries. A lso large crossindustrial transferability emerges. Furthermore, large companies appear to be more oriented to the paradigm than small ones. On the whole, process ownership is not very much implemented at the moment. It is expected to be the most difficult part of the paradigm to reach, given that the orientation to the multi-focused manufacturing paradigm is a step-by-step process rather than a radical "turn-key" switch. In addition, big differences across countries have been found about process ownership, which requires more interpretation on the basis of cultural and institutional differences. The empirical evidence also suggest that a higher degree of belonging to the paradigm results in a higher performance improvement. This leads us to conclude that the three principles re-enforce one another. Finally, the existence of different innovation tracks to approach the multi-focused manufacturing paradigm supports the idea that it does not act as a new "one best way" to organize manufacturing activities, but actually provides considerable space for different manufacturing strategies. Further investigation is currently performed on this issue.

\section{References}

1. Roobeek, A .J.M., "The crisis in Fordism and the rise of a new technological paradigm", Futures, A pril 1987, pp. 129-54.

2. Kenney, M. and Florida, R., "Japan's role in a post-Fordist age", Futures, A pril 1989, pp. 136-51.

3. Jaikumar, R., "Postindustrial manufacturing", Harvard Business Review, NovemberDecember 1986, pp. 69-76.

4. Drucker, P.F., "The emerging theory of manufacturing", Harvard Business Review, M ayJune 1990, pp. 94-102.

5. Hayes, R.H., W heelwright, S.C. and Clark, K.B., Dynamic M anufacturing. Creating the Learning Organization, The Free Press, N ew York, NY, 1988.

6. Slack, N., "F lexibility as a manufacturing objective", International lournal of Operations \& Production Management, Vol. 3 No. 3, 1983, pp. 4-13.

7. Stalk, G. Jr and Hout, T.M., Competing against T ime, Free Press, New York, NY, 1990. 
8. Piore, M . and Sabel, C., The Second Industrial Divide: Possibilities for Prosperities, Basic Books, New York, NY, 1984.

9. Womack, J.P., Jones, D.T. and Ross, D., T he Machine that Changed the World, Macmillan, London, 1990.

10. Doshe, $K$., Jurgens, $U$. and M alsch, T., "F rom Fordism to Toyotism? The social organization of the labour process in the Japanese automobile industry", Politics and Society, Vol. 14 No. 2, 1985, pp. 115-46.

11. Skinner, W., M anufacturing: the Formidable Competitive Weapon, John Wiley $\&$ Sons, New York, NY, 1985.

12. Hill, T., M anufacturing Strategy, Macmillan, Basingstoke, 1985.

13. Hayes, R. and Wheelwright, S.C., Restoring Our Competitive Edge, Competing through M anufacturing, John Wiley \& Sons, New York, NY, 1984.

14. Draaijer, D., "Market-oriented manufacturing systems", PhD thesis, University of Twente, Enschede, 1993.

15. Pfeffer, J., "On usefulness of the concept", in Goodman, P.S. and Pennings, J.M. (E ds), N ew Perspectives on Organizational Effectiveness, Jossey-Bass, San Francisco, CA, 1977.

16. De M eyer, A . and Ferdows, K., "Influences of manufacturing improvement programmes on performances", International lournal of Operations \& Production M anagement, Vol. $10 \mathrm{No}$. 2, 1990, pp. 120-31.

17. Voss, C.A. and Blackmon, K., "Practice performance relationships in UK manufacturing industry", Proceedings 1st International EurOM A conference: Operations Strategy and Performance 27-29 June, Cambridge University Press, Cambridge, 1994, pp. 1-6.

18. Flynn, B.B., Bates, K.A., Schroeder, R. and Sakakibara, S., "World class manufacturing in the United States", Proceedings DSI, Vol. 2, 1989, pp. 880-82.

19. Ferdows, K. and De Meyer, A ., "Lasting improvements in manufacturing performance: in search of a new theory", lournal of Operations M anagement, Vol. 9 No. 2, 1990, pp. 168-84.

20. Perona, M., Spina, G. and Turco, F., "Success measure of just-in-time: shifting manufacturing trade-offs. A field research in Italy", in Shatir, A. (Ed.), Just-in-T ime M anufacturing Systems. Operational Planning and Control Issues, Elsevier, London, 1991.

21. Voss, C.A., "Successful implementation of new processes", Business Strategv Review, Spring 1992, pp. 29-44.

22. Bartezzaghi, E., "I nuovi modelli del manufacturing”, in Filippini, R., Pagliarani, G. and Petroni, G. (E ds), Progettare e gestire l'impresa innovativa, Etaslibri, Milano, 1992 (in Italian).

23. Schonberger, R.J., Building a Chain of Customers, The Free Press, N ew York, NY, 1990.

24. Zimmermann, H.J., Fuzzy Set Theory and Its A pplication, 6th ed., Kluwer A cademic Publishers, London, 1993.

25. Spina, G., "L'adozione del nuovo paradigma produttivo nell'industria di assemblaggio. Note metodologiche ed evidenze empiriche", Proceedings of the 5th A ilG A nnual M eeting, "Leve strategiche nei mercati integrati", Napoli, 1994, pp. 167-98 (in Italian).

26. Hamblin, D. and Lettman, A., "Performance causality in manufacturing research", Proceedings 1st International E urOM A conference: Operations Strategy and Performance 27-29 June, Cambridge University Press, Cambridge, 1994, pp. 409-14.

27. Granger, W.W.J., "Investigating causal relations by econometric models and non-spectral methods", E conometrica, Vol. 37, 1969, pp. 24-36.

28. Mintzberg, H., T he Structuring of the Organizations, Prentice-Hall, New York, NY, 1979.

29. Karlsson, C., "Radically new production systems", International Journal of Operations \& Production M anagement, Vol. 16 No. 11, 1996. 


\section{Appendix 1.}

40
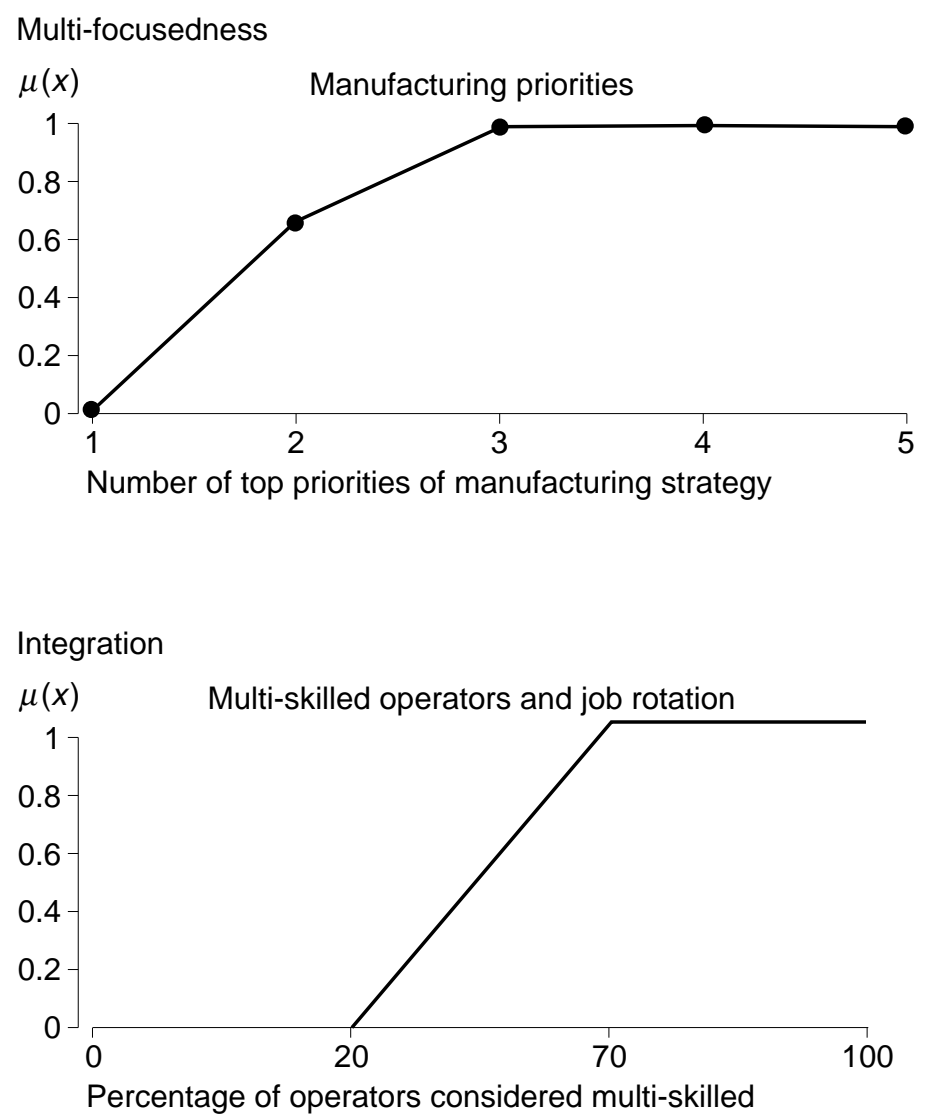

Process ownership

Figure A 1.

The membership functions (some examples)

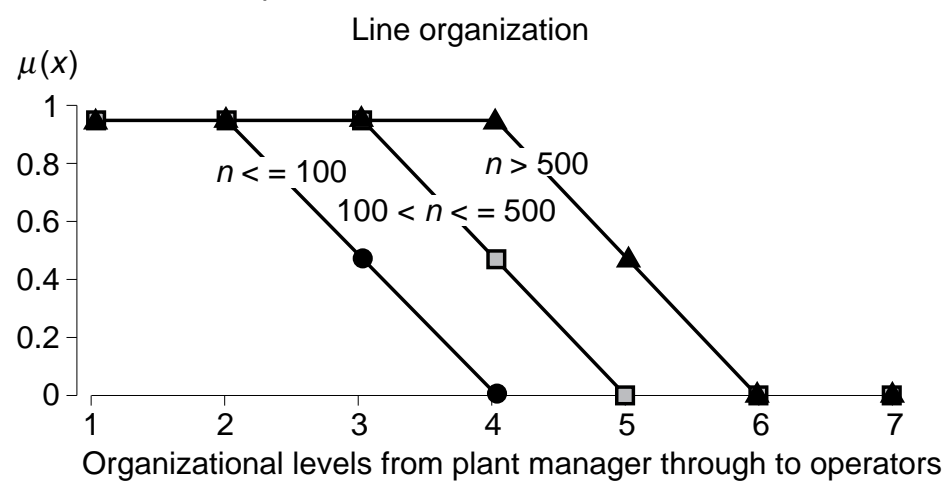

Note: $n=$ number of salaried employees in the business unit 


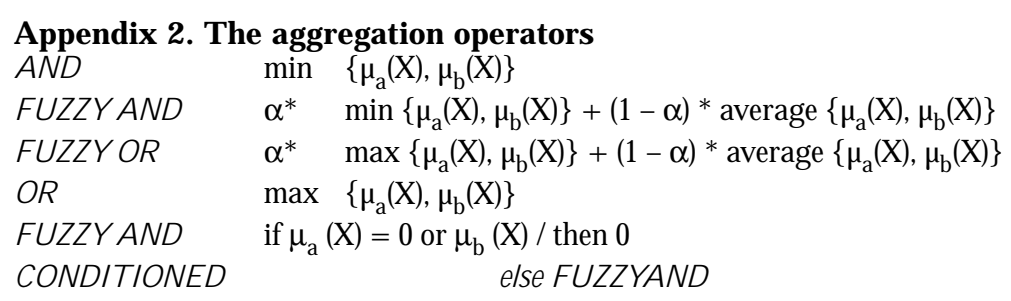

\section{A ppendix 3. The dropping procedure}

The standard procedure used to select processable companies is aimed at determining which are the companies that can be assigned a correct score as adopters or non-adopters of the paradigm. The problem concerns missing answers to some of the questions used in the filter. The following rules were used when processing a single company:

- a missing value prevails over a zero value (non-orientation to the paradigm) if they are combined either through an OR or a FUZZY OR,

- a missing value prevails over a generic non-zero value (some orientation to the paradigm) if they are combined either through an A ND or a FUZZY AND,

- in the other cases it is possible to evaluate correctly the fuzzy score of the aggregation of a missing information with whatever data. In fact, "missing" or "non-zero" $\Rightarrow$ "non-zero" and "missing" and "zero" $\Rightarrow$ "zero";

- this algorithm is pushed from the leaves of the filter up to the three basic principles of the paradigm;

- a company is discarded if it is impossible to assign a fuzzy score to each of these principles. 


\section{This article has been cited by:}

1. Paul Hong, Sandeep Jagani, Jinhwan Kim, Sun Hee Youn. 2019. Managing sustainability orientation: An empirical investigation of manufacturing firms. International Journal of Production Economics 211, 71-81. [Crossref]

2. Angappa Gunasekaran, Yahaya Y. Yusuf, Ezekiel O. Adeleye, Thanos Papadopoulos, Dharma Kovvuri, Dan'Asabe G. Geyi. 2018. Agile manufacturing: an evolutionary review of practices. International Journal of Production Research 121, 1-21. [Crossref]

3. J. Hill, A. J. Thomas, R. K. Mason-Jones, S. El-Kateb. 2018. The implementation of a Lean Six Sigma framework to enhance operational performance in an MRO facility. Production \& Manufacturing Research 6:1, 26-48. [Crossref]

4. ThomasAndrew, Andrew Thomas, AntonyJiju, Jiju Antony, Haven-TangClaire, Claire Haven-Tang, FrancisMark, Mark Francis, FisherRon, Ron Fisher. 2017. Implementing Lean Six Sigma into curriculum design and delivery - a case study in higher education. International Journal of Productivity and Performance Management 66:5, 577-597. [Abstract] [Full Text] [PDF]

5. Reza Aboutalebi. The Taxonomy of International Manufacturing Strategies 17-41. [Crossref]

6. A. J. Thomas, M. Francis, R. Fisher, P. Byard. 2016. Implementing Lean Six Sigma to overcome the production challenges in an aerospace company. Production Planning \& Control 1-13. [Crossref]

7. Harry Boer. Advanced Manufacturing Technologies and Strategically Flexible Production. A Review and Outlook 71-110. [Crossref]

8. Emilio Bartezzaghi, Raffaella Cagliano, Federico Caniato, Stefano Ronchi. Gianluca Spina’s Contribution to Manufacturing and Supply Chain Strategy Research and Management Education 1-16. [Crossref]

9. Chris A. Voss. Strategically Flexible Production: The Multi-focused Manufacturing Paradigm. A Review and Outlook 41-69. [Crossref]

10. Andrew Thomas, Duc Truong Pham, Mark Francis, Ron Fisher. 2015. Creating resilient and sustainable manufacturing businesses - a conceptual fitness model. International Journal of Production Research 53:13, 3934-3946. [Crossref]

11. Doordarshi Singh, Jaspreet Singh Oberoi, Inderpreet Singh Ahuja. 2013. An empirical investigation of dynamic capabilities in managing strategic flexibility in manufacturing organizations. Management Decision 51:7, 1442-1461. [Abstract] [Full Text] [PDF]

12. Eduardo Castellano, Juan Manuel Besga, Jone Uribetxebarria, Eduardo Saiz. Supply Network Configuration 73-106. [Crossref]

13. Yeming Gong. Competency-Based Fundamentals 101-140. [Crossref]

14. Thomas Friedli, Günther Schuh. Einleitung 1-26. [Crossref]

15. Raffaella Cagliano, Federico Caniato, Ruggero Golini, Annachiara Longoni, Evelyn Micelotta. 2011. The impact of country culture on the adoption of new forms of work organization. International Journal of Operations \& Production Management 31:3, 297-323. [Abstract] [Full Text] [PDF]

16. Stefan Seuring. 2009. The product-relationship-matrix as framework for strategic supply chain design based on operations theory. International Journal of Production Economics 120:1, 221-232. [Crossref]

17. Mariano Corso, Luisa Pellegrini. 2007. Continuous and Discontinuous Innovation: Overcoming the Innovator Dilemma. Creativity and Innovation Management 16:4, 333-347. [Crossref]

18. S.M. Moattar Husseini, C. O’Brien, S.T. Hosseini. 2006. A method to enhance volume flexibility in JIT production control. International Journal of Production Economics 104:2, 653-665. [Crossref]

19. Adegoke Oke. 2005. A framework for analysing manufacturing flexibility. International Journal of Operations \& Production Management 25:10, 973-996. [Abstract] [Full Text] [PDF]

20. Raffaella Cagliano, Nuran Acur, Harry Boer. 2005. Patterns of change in manufacturing strategy configurations. International Journal of Operations \& Production Management 25:7, 701-718. [Abstract] [Full Text] [PDF]

21. Zhongjun Tang, Rongqiu Chen *, Xuehong Ji. 2005. An innovation process model for identifying manufacturing paradigms. International Journal of Production Research 43:13, 2725-2742. [Crossref]

22. Anders H. Petersen, Harry Boer, Frank Gertsen. 2004. Learning in different modes: the interaction between incremental and radical change. Knowledge and Process Management 11:4, 228-238. [Crossref]

23. Petri Helo. 2004. Managing agility and productivity in the electronics industry. Industrial Management \& Data Systems 104:7, 567-577. [Abstract] [Full Text] [PDF]

24. Daniel Arias Aranda. 2003. Service operations strategy, flexibility and performance in engineering consulting firms. International Journal of Operations \& Production Management 23:11, 1401-1421. [Abstract] [Full Text] [PDF]

25. Krsto Pandza, Stuart Horsburgh, Kevin Gorton, Andrej Polajnar. 2003. A real options approach to managing resources and capabilities. International Journal of Operations \& Production Management 23:9, 1010-1032. [Abstract] [Full Text] [PDF] 
26. John Baldwin, Zhengxi Lin. 2002. Impediments to advanced technology adoption for Canadian manufacturers. Research Policy 31:1, 1-18. [Crossref]

27. A. De Toni, S. Tonchia. 2002. New production models: A strategic view. International Journal of Production Research 40:18, 4721-4741. [Crossref]

28. Kostas S. Metaxiotis, Kostas Ergazakis, John E. Psarras. 2001. An elaborate analysis of production systems in industry: what a consultant should know. Industrial Management \& Data Systems 101:4, 185-193. [Abstract] [Full Text] [PDF]

29. Michael A. Lewis. 2000. Lean production and sustainable competitive advantage. International Journal of Operations \& Production Management 20:8, 959-978. [Abstract] [Full Text] [PDF]

30. Raffaella Cagliano, Gianluca Spina. 2000. Advanced manufacturing technologies and strategically flexible production. Journal of Operations Management 18:2, 169-190. [Crossref]

31. Roger Beach, Alan P. Muhlemann, David H.R. Price, Andrew Paterson, John A. Sharp. 2000. Manufacturing operations and strategic flexibility: survey and cases. International Journal of Operations \& Production Management 20:1, 7-30. [Abstract] [Full Text] [PDF]

32. Emilio Bartezzaghi. 1999. The evolution of production models: is a new paradigm emerging?. International Journal of Operations \& Production Management 19:2, 229-250. [Abstract] [Full Text] [PDF]

33. Gianluca Spina. 1998. Manufacturing paradigms versus strategic approaches: a misleading contrast. International Journal of Operations \& Production Management 18:8, 684-709. [Abstract] [Full Text] [PDF]

34. Emilio Bartezzaghi, Gianluca Spina, Roberto Verganti. 1997. Strategically flexible production and the extra-firm infrastructures: how regions become attractive. Integrated Manufacturing Systems 8:5, 333-346. [Abstract] [Full Text] [PDF] 